\title{
Zur Kenntnis des kolloïdalen Silbers.
}

Von

E. A. SCHNEIDER.

Über die Lösungen des kolloidalen Silbers in Athylalkohol wurde schon vor einiger Zeit Mitteilung ${ }^{1}$ gemacht. Seitdem sind weitere Versuche über die Löslichkeit des Silbers in organischen Flüssigkeiten angestellt worden.

$\mathrm{Je} 1 \mathrm{ccm}$ des Organosols $\mathrm{Ag}\left(\mathrm{C}_{2} \mathrm{H}_{5} \mathrm{OH}\right)$, welches im Liter $3.424 \mathrm{~g}$ Ag enthielt, wurde im Reagenzrohre mit $5 \mathrm{ccm}$ des Lösungsmittels versetzt. Bei dieser Konzentration konnte bequem beobachtet werden, ob Koagulation eintrat oder nicht. Nur in einigen Fällen wurde mit leichter zugänglichen Lösungsmitteln das betreffende Organosol in reinem Zustande dargestellt. Im übrigen begnügte man sich mit der Beobachtung, ob Koagulation eintrat oder nicht, weil daraus mit einiger Sicherheit geschlossen werden konnte, ob das betreffende Organosol existenzfähig ist oder nicht.

Keine Koagulation wurde bewirkt durch:

Propylalkohol, Isobutylalkohol, Tertiären Butylalkohol, Cetylalkohol (in alkoholischer Lösung), Äthylenalkohol, Glycerin, Phenol.
Koagulation trat ein nach einigen Stunden auf Zusatz von:

Trimethylamid, Pyridin.
Isopropylalkohol,

Normalen u. sekundären Butylalkohol,

Trimethylkarbinol,

Heptylalkohol,

Octylalkohol,

Allylalkohol,

Erythrit,

Oktan,

Amylen,

Formaldehyd,

Önanthol,
Sofortige Koagulation wurde bewirkt durch:

Aceton,

Äthyläther,

Eisessig,

Benzol,

Benzylalkohol,

Metakresol,

Triäthylamin, Dimethylanilin, Diäthylanilin, Chinolin.

Die Beobachtung der Lösungen, in welchen keine Koagulation eingetreten war, wurde mehrere Monate hindurch fortgesetzt. Es

1 Ber. deutsch. chem. Ges. 24, 3370; 25, 1164, 1281, 1440. 
wurde bemerkt, dafs Phenol nach 14 Tagen einen koagulierenden Einflufs auszuäben begann; eine Woche später war die Koagulation deutlich sichtbar. Einen Monat nach Beginn des Versuches konnte man in den mit Propylalkohol und tertiärem Butylalkohol versetzten Lösungen Anzeichen einer Koagulation bemerken. Nach weiteren zwei Monaten war in allen Lösungen Koagulation eingetreten. Nur das Koagulum durch Glykol war wasserlöslich, während in allen anderen Fällen das Koagulum sich mit dem ursprünglichen Farbenton in Wasser löste.

Das Organosol $\mathrm{Ag}\left(\mathrm{C}_{3} \mathrm{H}_{5}[\mathrm{OH}]_{3}\right)$ wurde durch Abdunsten eines Gemisches gleicher Volumina des Organosol $\mathrm{Ag}\left(\mathrm{C}_{2} \mathrm{H}_{5} \mathrm{OH}\right)$ und Glycerin in Vakuum äber Schwefelsäure dargestellt. Nach Verlauf mehrerer Monate konnte in demselben noch keine Sedimentation wahrgenommen werden.

Ein systematisches Studium des Verhaltens der Kolloïde gegenüber organischen Lösungsmitteln verspricht interessante Resultate $z u$ geben, wenn es gelingen sollte, eine gewisse Gesetzmälsigkeit zu entdecken. Vorläufig konnte konstatiert werden, dafs verschiedene Kolloïde sich nicht gleichmälsig gegenüber denselben Lösungsmitteln verhalten. Wenigstens gelang es bis jetzt nicht, ein Organosol der Zinnsäure in Äthylalkohol darzustellen, während ein aufserordentlich beständiges Organosol mit Glycerin erhalten werden konnte.

In meinen früheren Mitteilungen ${ }^{1}$ über das kolloïdale Silber wurden die Eigenschaften des Kollöles in völlig trockenem Zustande nicht besprochen, weshalb sie bei dieser Gelegenheit erwähnt seien.

Eine grölsere Menge des Organosols $\mathrm{Ag}\left(\mathrm{C}_{2} \mathrm{H}_{5} \mathrm{OH}\right)$ wurde mit absolutem Äther koaguliert, der Niederschlag durch Dekantieren mit Äther gewaschen und im Vakuum über Schwefelsäure getrocknet. Das trockene Kollord zeigte einen grünlichen Metallschimmer. Der Glühverlust betrug $4.5 \%$. Beim Erhitzen wurde das Auftreten eines brenzlichsauren Geruches wahrgenommen. In einer mit Wasserdampf gesättigten Atmosphäre nahm es im Laufe von drei Tagen um $15.52 \%$ an Gewicht zu.

Das durch Äther gefällte und sodann getrocknete Kolloild löste sich vollkommen in Wasser.

1 l. c.

Bei der Redaktion eingegangen am 14. September 1894. 